\title{
Anti-CD133-CAR Vector-transduced Allogeneic T Lymphocytes
}

National Cancer Institute

\section{Source}

National Cancer Institute. Anti-CD133-CAR Vector-transduced Allogeneic T Lymphocytes. NCl Thesaurus. Code C124132.

A preparation of allogeneic peripheral blood T-lymphocytes (PBTL) that have been genetically modified to express a chimeric antigen receptor (CAR) specific for the chimeric CD (cluster of differentiation) 133 antigen receptor, with potential immunostimulating and antineoplastic activities. Upon administration, anti-CD133-CAR vector-transduced allogeneic T-lymphocytes specifically recognize and kill CD133expressing tumor cells. CD133, a tumor associated antigen (TAA), is overexpressed on a variety of tumor cell types. 